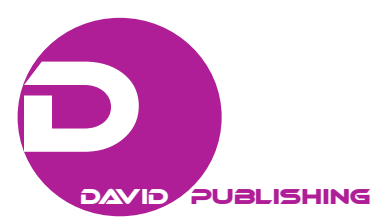

\title{
Intrinsic Contradictions of the Money Concept From Real Bill to Monetarism and Back Again
}

\author{
Rolf Hasse Erhard Ekstedt \\ University of Gothenburg, Gothenburg, Sweden
}

The Nobel laureate, Robert Lucas, declared 2003 in his presidential address to the American Economic Association, that the "central problem of depression-prevention has been solved, for all practical purposes, and has in fact been solved for many decades". Today we stand in front of severe social unease in most OECD-countries and military conflicts are more severe than in many years. What do the economic scientists say? What do they suggest? Nothing! Are there any economic models for solving the problems? Economics is a social science, but has forgotten this in the worshipping of "the market exchange" and the concept of equilibrium. This paper is a discourse of the economic theory in the light of the economic development after WW2. The focus is on the theoretical anomalies with respect to money in relation to the systemic changes of the financial sector from WW2 to the current structure. The globalized real development and ownership of capital imply that financial flows are less attached to real flows and furthermore that currencies and state securities became less secure. New financial technologies enforce new attitudes to money, finance, and financial control. The financial crises of 2008 showed the theoretical deficiencies of the ruling mainstream economic theory particularly in its attitude to the concept of money. The downgrading of the US 2011 by S\&P and the following turmoil showed the fragility and the chaotic structure of the apprehensions of the system. It is a bit ironic that the change of the global financial industry we experience today in its basic structure is similar to the system prevailing before 1810 and was advocated by Adam Smith, the so called Real Bill system. During the Napoleonic wars Britain's financial system became exhausted not to say chaotic. It became the task of the two leading economists, Henry Thornton and David Ricardo to design a new system where Bank of England was the controller of the new system and the final design was taken as a law 1844 Bank Charter Act. This was actually the formal birth of the modern structure of monetarist theory. Because of the increased global financial integration, which developed organically outside the control of national authorities due to new communication systems and some other technical innovations, we now have had a development back to something like the Real Bill system of pre-1810. This structural change calls for a definitive departure from the Monetarist theory, not necessarily by theoretical reason but because it does not fit into the current economic and financial structure.

Keywords: IS-LM-model, permanent employment, money, monetarism and real bill

\section{Introduction}

This paper is closely linked to many years research, which has resulted in four books. ${ }^{1}$ Fundamentally the

Rolf Hasse Erhard Ekstedt, senior researcher, School of Public Administration, University of Gothenburg, Gothenburg, Sweden.

Correspondence concerning this article should be addressed to Rolf Hasse Erhard Ekstedt, School of Public Administration, University of Gothenburg, Box 712, 40530, Gothenburg, Sweden.

${ }^{1}$ Ekstedt \& Westberg (1991), Ekstedt \& Fusari (2010), Ekstedt (2012), Ekstedt (2015). 
research has focussed on the necessary methodological differences between researches in social sciences, which deals with subjects who should be seen as final causes and thus complex variables and experimental natural sciences dealing with objects and which to a large extent are to be seen as atomic variables in an experimental design. The main issues have been the deficiency of the axiomatic structure of general equilibrium theory, the general theoretical as well as the intrinsic contradictions of the concept of money, the methodological deficiencies of the mathematical modelling, and the blurred concept of risk and uncertainty when using the concepts with respect to social sciences. To give a full view of methods and results is impossible in a limited paper.

However theoretical research implies muddling through axiomatic and logical structures and conceptual analysis, which is necessary, but one sometimes misses breathing the fresh air of the empirical world. So this paper has the aim to discuss the structural development of the real and financial markets since WW2. This is an exciting period which started more or less in chaos but developed into an exceptional global growth where the two first decades are called a period of an economic greenhouse (Eichengreen, 1995). But then the development was more or less brought to a halt and now many countries experience social unease or are at the brink of a break out of social unease. Much of the causes for the present political confusion of how to deal with the increasing social rifts within earlier stable countries come from a combination of austerity policy and supporting the banking system which has been on the brink of a collapse.

This intriguing period cannot be discussed other than through a historical description of the inter-relation between the real and financial development. Such an expose also displays the development of economic theory in its trying to explain structural changes outside the normal theoretical spheres. The main problem during the period since the 1970s has been stagflation and the increase of the permanent unemployment. The stagflation had two sides which were seemingly at variance with respect to available political means, so it was thought that if inflation was defeated the unemployment problem would be solved, if not automatically with smaller political efforts, since growth would increase. Today in the days of negative central bank interest rates we have obviously left the dogma low inflation - high growth for increase inflation-increase the growth. Seldom one sees efforts to unveil the structural changes which the global economy has experienced but more efforts to squeeze empirical events into an obsolete theory in order to explain developments of variable structures which are not present in the theory. The main stream economic theory, based on neoclassical general equilibrium analysis, still is obsessed with a barter economy suitable for a medieval village and cannot even properly discuss the concept of money within its frames.

The reason why we in the end focus on the financial side is that the most outspoken uncertainty of the future is displayed in the changed behaviour and roles of the financial actors. The most astonishing thing is that it seems like we are globally coming back to a financial structure prevailing before 1810 in England, the so called Real Bill system.

The historical development is partly from own studies and partly from comparing empirical studies in the OECD-area. The suggested current changes in the financial sector are gradual so it is a mixed structure but to understand the 2008 disaster it is necessary to understand the gradual transformation of the global financial system. What will happen in the future with respect to different kinds of state interventions, international agreements, we have already the Basel agreements, is impossible to say but the earlier path of austerity policy is probably a very doubtful way, and what is politically possible is to be seen. Otto von Bismarckt claimed that "Politik ist die Kunst des Möglichen", so what is possible now and in the future is probably rapidly changing, if we look at the current political evolution. 
The paper starts with an overview of approaches to money. The theoretical change at the end of the 19th century is stressed, from analysing Monetary Economy to an analysis of a Barter economy. Then it follows a historical overview of the period after WW2 and some empirical as well as theoretical effects which followed the sharp change in growth medio 1970s. This led to both political as well as theoretical limbo in the widespread occurrence of permanent unemployment which still is a plague, particularly among young people. Structurally it is relatively simple to explain it but to find viable political means is another thing.

This historical description is then the foundation for the theoretical analysis of money and financial structures and we introduce two theorems derived in Ekstedt (2015) of which the first deals with the barter economy in the light of Arrow's paradox which decouples the microscopic and the macroscopic levels given that we reject additive aggregation.

The second theorem implies that if we deal with a money economy in disequilibrium we still can use additive aggregation. The two propositions imply that in a barter economy where commodities are complex, not atomic, there exists no Pareto efficiency but if we do not care about whether or not we have a barter general equilibrium but analyse a money economy in disequilibrium, that is no unique price vector, we can allow additive aggregation since money values are defined in an atomistic way. Then we can prove a sort of Pareto efficiency with respect to money values and cost minimization. However this cost-minimization optimum has no welfare maximization dual.

We end the paper with an analysis of the ongoing structural changes at the financial market which seem to bring us back to a structure similar to the times before 1810, the Real Bill.

\section{Pecunia Non Olet $^{2}$}

The Roman Emperor Vespasianus answered so when the Senate criticised the decision to take a fee for visiting the small houses for Public Convenience, and so indeed it is. The real thing is separate from its money value.

Until the beginning of the 19th century philosophers and economic analysts regarded it as a tautology that the barter economy has particular characteristics not comparable with those of the money economy, this was a theoretical triviality.

Aristotle claimed:

But money has become a convention a sort of representative of demand; and this why it has the name "money" $(o ́ \mu 1 \sigma \mu \alpha)$ because it exists not by nature but by law (vó $\mu \circ \varsigma)$ and it is our power to change it and make it worthless. (Aristotle, p. 381, no. $1133^{\mathrm{a}}$ )

He proceeds:

When the use of coin had once been discovered, out of the barter of necessary articles arose the other art of wealth-getting, namely retail trade; which was at first probably a simple matter, but became more complicated as soon as men learned by experience whence and by what exchanges the greatest profit might be made. (Ibid., p. 451 , no. $1257^{\mathrm{b}}$ )

However in the 16th century Spain had a great inflow of wealth, particularly precious metals, from America which more or less forced the intellectuals, particularly in Spain and its leading university of Salamanca to analyse the ongoing economic dynamics. The inflow of precious metals didn't imply the expected

\footnotetext{
${ }^{2}$ Money does not smell.
} 
wealth and prosperity, neither for Spain nor for the majority of its population. Marjorie Grice-Hutchinson begins her book on the School of Salamanca by saying:

If there was one economic lesson which the whole Spanish nation had learned by the middle of the sixteenth century, it was that the value of money is fickle and that gold and silver are not synonymous with wealth, a lesson made all the more bitter by the high hopes that had attended the discovery of the New World a few decades before. The dream of El Dorado had been followed by a harsh awakening. (Grice-Hutchinson, 1952, p. 1)

The theorists at Salamanca realised however the need of financial markets and money exchange and were consequently more positive to its existence then Aristotle. Martin de Azpilcueta Navarro accepts the Aristotelian description of the development of money but in making a reference to his own time he observes that

...money of a particular country came to be worth less there than abroad (as today nearly all the gold and silver of Spain is worth less in Spain than in Flanders and France), there came into being the art of exchange, which is the art of giving and taking one kind of money in exchange for another. (Ibid., p. 90)

And continues:

Nor is it true that to use money by changing it at a profit is against nature. Although this is not the first and principal use for which money was invented, it is none the less an important secondary use. (Ibid., p. 91)

Smith and Hume saw the full transformation of the barter economy to a money economy and particularly Hume claimed that the money economy would be a necessary step in civilizing the society. As Adam Smith, Hume sees the industriousness of people and their free disposal of what is produced for own purposes or taking it to the market, as the basic wealth of a society.

Money is not, properly speaking, one of the subjects of commerce; but only the instrument which men have agreed upon to facilitate the exchange of one commodity for another. It is none the wheels of trade: It is the oil which renders the motion of the wheels more smooth and easy. (Hume, 1770, Essay I of Commerce, p. 45)

The three great analysts in the beginning of the 19th century: Thornton, Ricardo, and Say who will be more commented upon later, laid the foundation of the analysis of the monetary economy and particularly Thornton and Say, were moreover a kind of disequilibrium theorists, although general equilibrium neoclassical sense did not exist as a scientific concept.

In the so called marginal revolution in the middle/end of the 19th century something happened: in the spirit of physical science, economists tried to create a closed self-propelling system à la Newton, which granted that the highest form of productive efficiency could be reached. This system was built on the free market of exchange. It is instructive to read Mill (1990 [1863]), and Jevons (1888 [1871]) to compare the discussions of the ideal form of a utilitarian social analysis of Mill with Jevons impressive mathematical effort to make a mathematical model out of it. Jevons had to capitulate, since he was an able mathematician, and transform Mill's grande views into a system which after elaboration into the so called Arrow/Debreu general equilibrium model 1977, was proven, by two Soviet mathematicians Makarov and Rubinov (1977), not to be able to discriminate between a centrallized Soviet command economy and a market economy according to Jevons' utilitarian formalizations.

However this model, called the neoclassical general equilibrium theory, is built on six axioms, which transform the commodity space into a Euclidian space and the agents into commodity vectors, is unable to 
handle the concept of money. Thus, basically the main-stream economic theory, which is built on the neoclassical theory, is theoretically unable to handle the problem which already Aristotle posed about the different intrinsic characteristics of money.

The Keynesian theory uses money in the form of liquidity but seldom elaborates the intrinsic contradiction between money as a medium of exchange on liquidity in debt and even more seldom between money as a medium of exchange and at the same time the measure of intertemporal assets and debts. Kenneth Arrow and Frank Hahn (1971) wrote in the concluding chapter with the title "The Keynesian Model": "If a serious monetary theory comes to be written, the fact that contracts are made in money will be of a considerable importance" (Arrow \& Hahn, 1971, pp. 356-357).

Today we have two branches of economic analysis: economic theory and money/financial theory. Already Aristotle envisaged a rift between these two branches, the two are more or less incommensurable. When speaking of general equilibrium in the neoclassical sense it is seldom commented upon the fact that while financial equilibrium relative to contextual changes almost at the speed of light settle revaluations of assets and liabilities, while the real economy is hardly affected (if it is affected at all) until several months have passed. Thus there is an incredible discrepancy between the reaction speed of the real sector and the valuation of assets and liabilities. To claim that the entire economy could reach a prevailing general equilibrium is certainly very brave, to say the least.

On the other hand we cannot understand any of the two sides without taking the other into consideration. The author's professor in the late 1960s said: "The real side of the economy is the important one but nothing could be said about it without understanding money." This holds also today.

\section{Historical Background}

\section{The Rise and Fall of the IS-LM Model}

In the aftermath of WW2, the western world generally applied a sort of mixture between the neoclassical theory and Hicks' (1937) apprehension of Keynes' thoughts, particularly in The General Theory of Employment, Interest, and Money, after some modifications, adding money market and demand for liquidity, it became the so called IS-LM model, which became a sort of normative theoretical approach to economic policy recommendations.

The IS-LM model was primarily a short run model based on assumptions of a constant technology and a constant potential supply, the investments only added very marginally to the production capacity in the short run. This meant that the aggregate demand was the key variable determining the volume of labour demand. Implicitly it also meant that labour was a homogenous production factor (as also capital was, with respect to eventual short run structural shifts in the demand).

The money sector built on Fisher's equation completed with interest rates which was the link to the investment behaviour and eventual speculative/cautiousness motives for holding money. Thus, the IS-LM model was a closed equilibrium model with respect to exogenous demand variations where the policy authorities have three means: interest rate, tax rate, and the volume of public demand. It is different from the neoclassical model in the sense that the market system is not self-stabilizing due to exogenous shocks, thus supply and consequently profits are residuals and not because of a global optimization process.

The policy based on these principles of modelling worked out reasonably well for most of the OECD countries during the 1950s to the beginning of the 1970s but the reason for this was hardly the model structure 
per se but the very economic and political structure during these decades. Two conditions were of utmost importance. First, there was a systematic excess demand in virtually all sectors after the war. There was an ongoing structural change but this had no negative effects on the employment but was parallel to the general expansion of the production systems. Eichengreen (1995) called the economic post-WW2 development for a "greenhouse effect". The second condition was the Bretton Woods system which minimized the currency risks and led to a formidable expansion of international trade.

Figures 1 and 2 display the growth of world GDP and world trade respectively, based on IMF-statistics. The geometrical form of the curves, particularly in Figure 2, is intriguing.

Calculating the growth function between the end points for the respective series result in a growth rate during the total period is $3.99 \%$ for the World GDP and $6.1 \%$ for World trade.
E1:$$
E Q^{t}=26 \cdot e^{0.039872 \cdot t} ; E W T^{t}=12 \cdot e^{0.061066 \cdot t}
$$

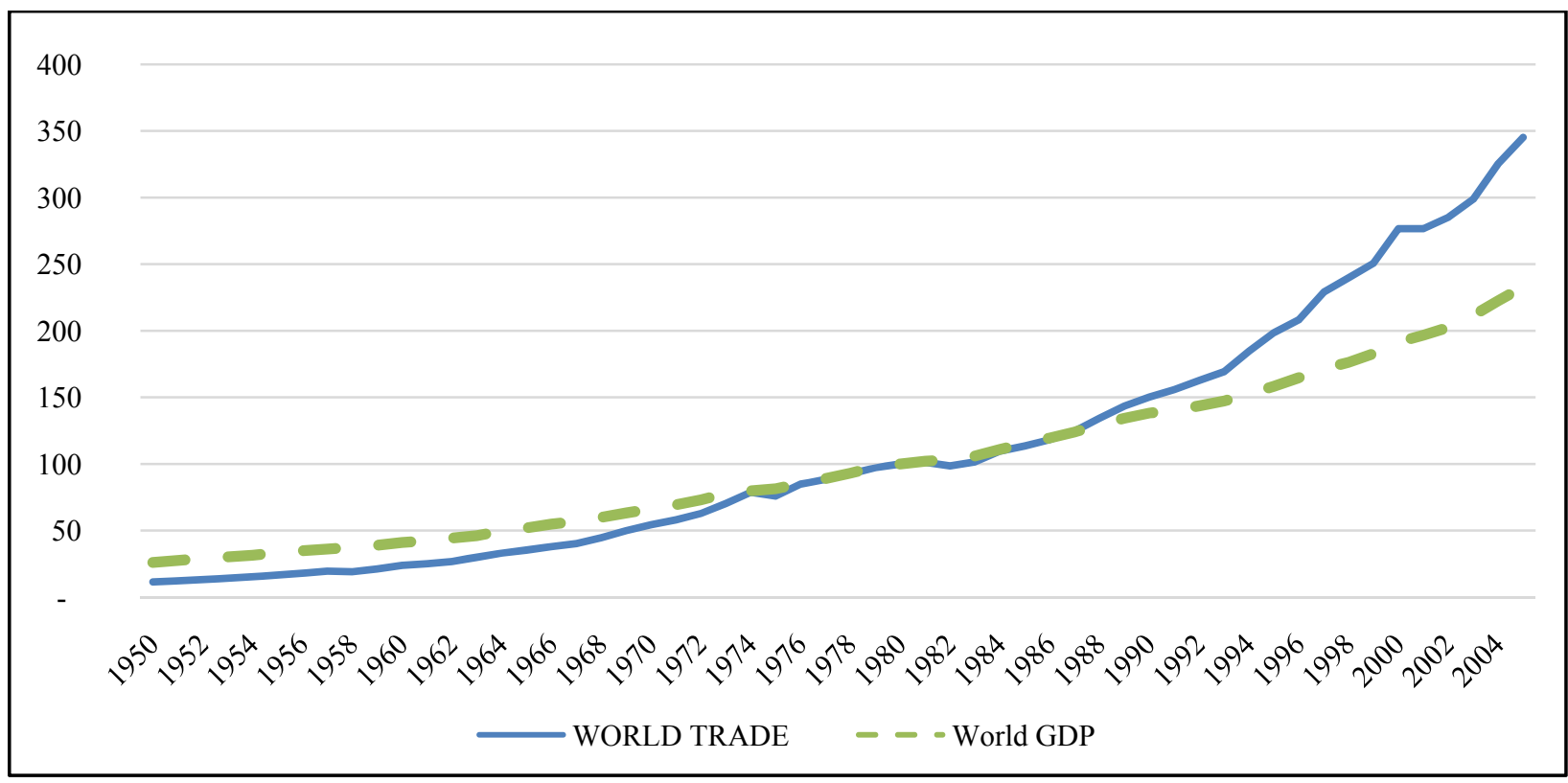

Figure 1. Growth of World Trade and World GDP from 1950 to 2005. $1980=100$. Source: IMF-statistics.

One may now take the quota between the yearly numbers given in the IMF-statistics and those obtained by the growth function and plot the relations as in Figure 2. This shows that the form of deviation from the respective exponential function is virtually the same for both variables, a higher growth rate from 1950 to 1972/74 and then a decreasing growth rate until 2005. The World Trade shows however a more pronounced development.

From an economic policy point of view the employment variations were basically short-run and could be met by short run means. The inflation was important since the Bretton Woods system implied that higher and prolonged inflation in a certain country weakened the international competitive strength. But the effects of inflation were "slow" in the sense that inflation differences with respect to relative prices are on one hand asymmetric and on the other hand detectable only after a considerable time. Thus, the inflation policy could be pursued to attain effects after a considerable time. Monetary and fiscal policy could be coordinated and the monetary policy was not only directed to the inflation problem but mainly to stimulate investments and indirectly the employment. 


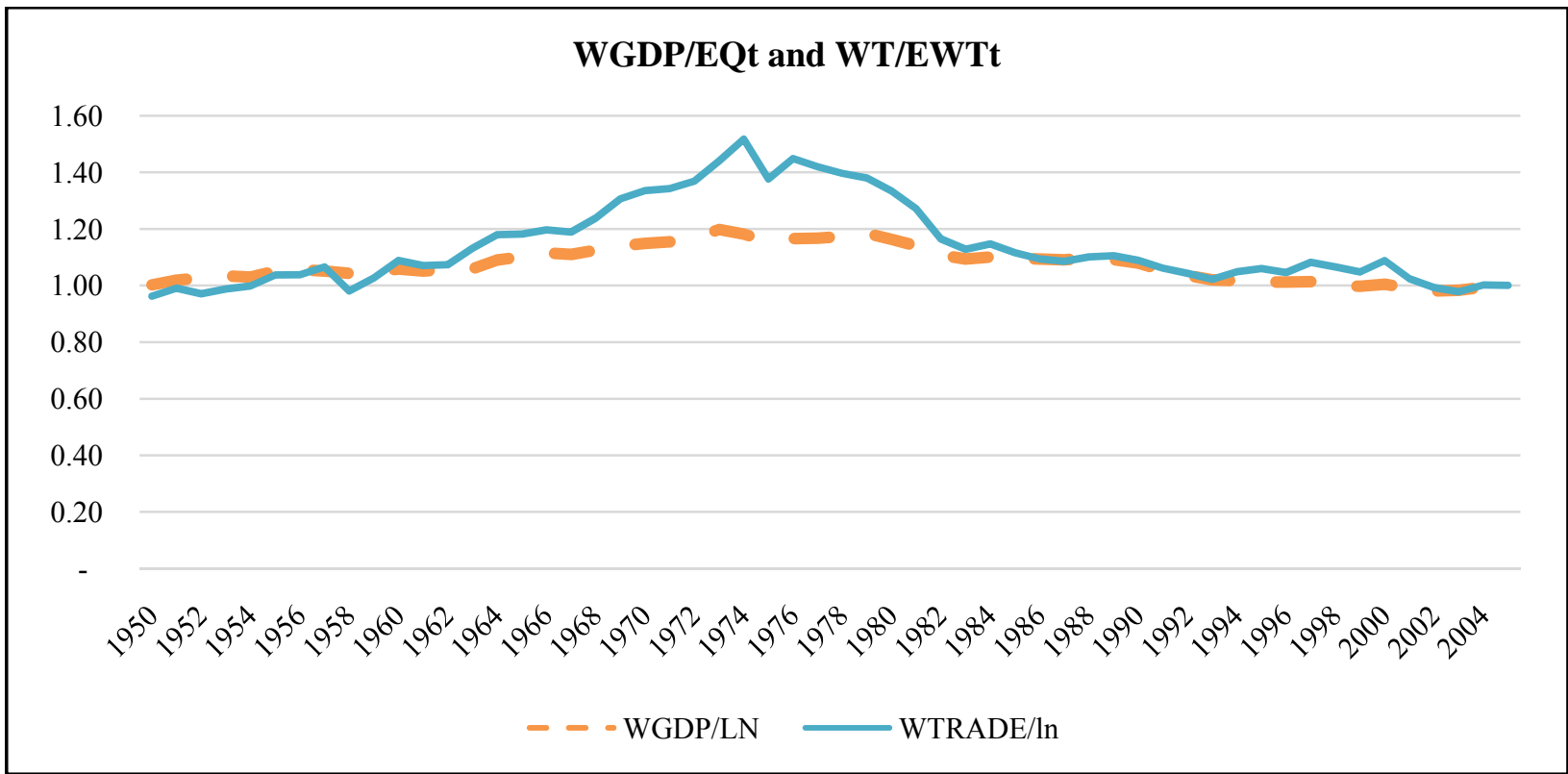

Figure 2. Relative growth of Trade and GDP. Source: IMF-statistics and own calculations.

During this "greenhouse" period the aggregate demand variated around the potential supply which also practically coincided with the optimal capacity utilization of the capital stock.

But this happy period ended. According to several studies (Lundberg, Ohlin, \& Werin, 1975; Boltho, 1982; Ekstedt \& Westberg, 1991; Eichengreen, 1995), this period ended in the end of 1960s/beginning of the 1970s since the international supply was balancing the international demand, and then the general excess demand vanished. Simultaneously the Bretton Woods system ran into difficulties and was abolished in the beginning of 1971.

In this situation, the economies of the USA and Western Europe experienced a change from general excess demand and stable currencies to a more competitive international market combined with higher currency uncertainty, which developed into higher financial uncertainty in toto. From 1972 to 1979 we had a completely new currency scenario, a mixture of floating currencies, unilateral basket currencies, groups of countries trying to have semifixed currencies while floating in relation to non-participants in the group. At the same time, we got the so-called oil-crises which irrespective of its causes brought the energy/technological uncertainty at the top of the business agenda.

\section{Theoretical Limbo-Permanent Unemployment}

Consequently, during the 1970s it was a substantial increase in general business uncertainty due to (i) increased competition on the market combined with a changing market structure; (ii) increased technological uncertainty particularly with respect to energy; (iii) increased uncertainty on the international financial market. This combination is almost lethal; increase in short term real uncertainty combined with increase in long run real uncertainty combined with increase in both short and long run financial uncertainty, which is increased uncertainty with respect to the only asset which may insure against increased real uncertainty. Due to the currency unease, even liquidity in its deepest form was subsequently hit.

Theoretically the Keynesian economics, Hick's variant of IS-LM, was doomed, since the occurred economic problems were due to deep-going structural shifts both with respect to market structures as well as 
feasibility of policy. A whole bouquet of approaches replaced it such as new classical economics, monetarism, rational expectations, Laffer curve, and other theoretical passing fancies, some dissipative and some more inert.

One of the reasons why the old-fashioned IS-LM principle became obsolete was that it contained no microscopic foundation. As such a foundation, the traditional neo-classical theory entered as the new fashion of thought among market-orientated macro-economists. ${ }^{3}$ Principally this was a bit curious since the IS-LM approach was at the beginning to be a compromise between Keynesian thinking and the neoclassical theory. ${ }^{4}$

Certainly, however, microscopic structural analysis of the development was lacking among the macro-economists. It appeared many good microscopic analyses, like Caves' and Bower's analysis of industrial structure, Becker's Houshold production theory, but these were seldom affecting the macroscopic analysis. However, to claim that the simple neoclassical model in its axiomatic form had anything to say was a misjudgement, unfortunately rather inert.

Thus, there were two real processes. The first was of course to increase productivity by technology changes and consequently an increase of competitiveness. The second was an overall process to decrease the potential production capacity. The latter was done via ordinary competitive patterns, but also through mergers and acquisitions. The macroeconomic consequences however implied that permanent unemployment was more or less built into the industrial structure. Figure 3 illustrates the process diagrammatically. ${ }^{5}$

The volumes of labour $\mathrm{L}_{0}^{*}$ and $\mathrm{L}_{0}{ }^{2}$ indicate the degree of labour hoarding for the short run functions $\left\{\frac{Q}{L}\right\}_{s h}^{*}$ and $\left\{\frac{Q}{L}\right\}_{s h}^{2}$ respectively while the $L^{*}$-volume indicates optimal production at the respective function for $\left\{\frac{Q}{L}\right\}_{s h}^{*}$ and $\left\{\frac{Q}{L}\right\}_{s h}^{1}$ respectively and the market labour demand is equal to the socially feasible demand equal to $L^{*}$.

The process we are to describe traces its roots far back in history. Both Hume and Ricardo discuss the effects of technical change and are very clear that technical change has both labour saving effects as well as capacity increasing effects, however these aspects have deepened and become more complex during the late 20th and early 21 st centuries. In Figure 3 the essential characteristics of the process are described.

During the whole period since WW2 we have had a process of increasing heterogeneity of labour; this is not only the case for capital intensive processes but also for the service sector. ${ }^{6}$ During the 1950 s up to the middle of the1970s there were rather few visible signs of this since we had an overall excess demand which made the economy rather like a neoclassical ideal, where surplus labour in one sector could find jobs in other growing sectors. However, from the middle of the 1970s and onward this aspect has been increasingly important and in our days the problem of heterogeneity of labour is so great that firms prefer to keep special

\footnotetext{
3 Among theoreticians there were a very interesting debate following the classical work by Arrow \& Hahn (1971), particularly Sonnenshein (1972), McFadden, MasCollell, Mantel, \& Richter (1974), Mantel (1974) in a discussion on the existence of aggregate market excess demand functions where also Arrow added an extremely important paper in 1986 with the intriguing title: Rationality of Self and Others in an Economic System. As a matter of fact this discussion, if it had been taken seriously it had taken economic theory in another direction which had possibly affected economic policy in some interesting ways. Rizvi Abu Turab, S. (2006) has a very interesting retrospective discussion of this discussion.

4 Hicks confesses (1980) that his paper "Mr Keynes and the Classics" did not get the gist of Keynes analysis.

5 The basic model of thinking is from Ekstedt \& Westberg (1991, ch. 2) but was developed in Ekstedt \& Fusari (2010, ch. 7) and partly also in Ekstedt (2012, ch. 4).

${ }^{6}$ Even Hume and Ricardo discuss this matter on heterogeneous labour. Smith mentions it too but he is more occupied with rural conditions and British trade policy.
} 
labour although decreasing sales of the product, so called labour hoarding. The time for on the job training is too costly compared with keeping labour with special characteristics. So it is not only for the capital-intensive industry but also for the labour intensive to a rather high degree. The problem is nowadays rather well-known and in Ekstedt (2015, pp. 241-251) the problem is discussed extensively. Unfortunately, this is mostly discussed by so called labour market economists and has not entered the more general economic theorizing and macroscopic modelling to any high degree.

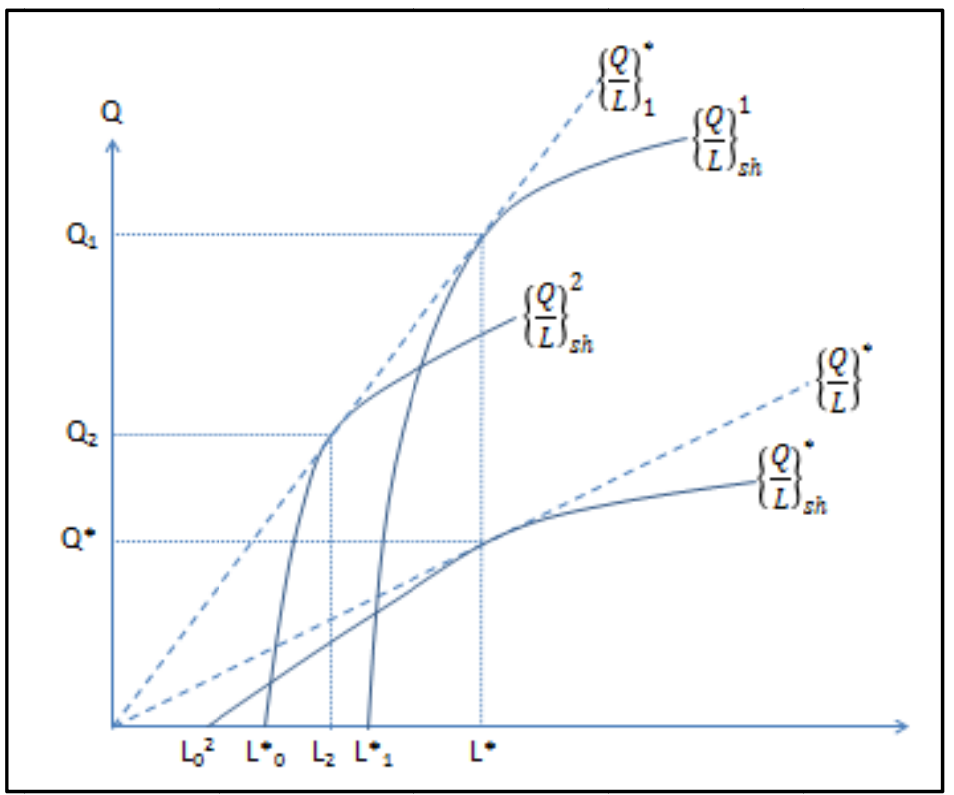

Figure 3. Productivity and permanent unemployment. Source: Ekstedt and Westberg (1991, pp. 43-67).

Looking at Figure 3 the effect of labour hoarding results in a short run fixed volume of labour, so we have a maximum physical average productivity which is decreasing on both sides. For the curves $\left\{\frac{Q}{L}\right\}^{*}$ and $\left\{\frac{Q}{L}\right\}_{s h}^{*}$ we have that at $\left(\mathrm{Q}^{*} ; \mathrm{L}^{*}\right)$ we have the maximum physical productivity. The short run dotted curve shows the variations in productivity due to labour hoarding and overutilization of capital on respective side. Thus, the price/wages movements are essential. Competing at the world market implies that the single firms behave like price-takers. In such a case variations in demand will imply variations in labour productivity as well as in the profit-share. This is to be separated from the profit-rate since variations in the profit-share imply that we have variations in the financial/liquidity positions of the firm. Figure 3 shows that if labour is to be a variable production factor, the demand variations, given the prices, will not affect the labour productivity and consequently not the profit share. If we on the other hand have a short-run production function as $\left\{\frac{Q}{L}\right\}_{s h}^{*}$ this will be the case. Such a case will affect the risk situation of the firm. ${ }^{7}$

One effect of the technological change in a broad meaning is thus that an increasing tendency of labour hoarding has accompanied the increasing general productivity. Together with increasing international competition this will lead to a higher risk of the production capital which will trigger a development of lower growth of the capital stock.

\footnotetext{
${ }^{7}$ In Ekstedt \& Fusari (2010, pp. 221-231) and Ekstedt (2012, pp. 145-155) the problem is discussed in depth.
} 
Figure 2 illustrates two periods: one between WW2 and middle of 1970s and the other from middle of 1970s up to now (although the diagrams 1 and 2 end at 2005). The first period, which Eichengreen called the green-house economy, let us for simplicity imagine the whole industry, we can then start from the point ( $\mathrm{L}^{*}$; $\mathrm{Q}^{*}$ ) which is the optimal, cost-minimization, utilization of the capital stock. In the period after WW2 the labour volume $\mathrm{L}^{*}$ was on the average around the socially desirable and feasible employment. An increase in labour productivity leading to the point $\left(\mathrm{L}^{*} ; \mathrm{Q}_{1}\right)$ was in fact possible since we had the systematic excess demand both in the form of volume and in the form of increasing dimensionality of the consumer basket. Thus, the effect of the increasing labour hoarding was unimportant/hidden in the general growth of the economy.

During the latter period, however we had a decreasing growth rate but an increased focus of competitive/cost-diminishing investments instead of capacity increasing. This had the result that the increased labour hoarding now became a source of increased variability of the profit-share and thus an increased uncertainty of the financial position of the firms. Consequently, the increase from ( $\left.\mathrm{L}^{*} ; \mathrm{Q}^{*}\right)$ became non-feasible and we got the development indicated by the arrow to $\left(\mathrm{L}_{2} ; \mathrm{Q}_{2}\right)$ where the optimal capital utilization leads to a substantially lower employment than $\mathrm{L}^{*}$.

The distance between the actual employment at optimal capacity utilization and the socially desirable employment can be called permanent unemployment ${ }^{8}$. The increasing heterogeneity of labour is indeed a problem for particularly small economies. In Europe, practically all economies are dependent on foreign trade and very competitive production branches and for a small country like Sweden it is a nightmare. Due to the hard foreign competition and dependence on the international financial system Sweden is not able to take proper measures of increasing another type of more internally demanded production since that would inevitably lead to heavy state deficits and private alternatives are not feasible due to high risk.

The difference between the roles of profit rate and profit share was not particularly discussed in economic analysis until the latest decades when the pro-cyclical variations in labour productivity were observed. One problem making things somewhat difficult nowadays is the very divided manner of the business cycle due to the global market influence of national markets. This implies that the patterns we have discussed may not appear in macroscopic statistics but need to be studied at the sectoral level, which particularly Navarro and De Soto (2006) discuss for the Chilean economy 9 .

\section{The Fundamental Failure of Economic Theory}

Such aspects as we have discussed in relation to Figure 3 hardly occur in the neoclassical theory and seldom in the Keynesian modelling but for different reasons. In the first approach, it cannot exist and in the second it is overlooked due to its microscopic character and the difficulty to find aggregate numerical representations. This discussion is a good example of what Keynes meant in his letter to Roy Harrod, 10th of July 1938 (Keynes Collected Works 1938):

My point against Tinbergen is a different one. In chemistry and physics and other natural sciences the object of experiment is to fill in the actual values of the various quantities and factors appearing in an equation or a formula; and the work when done is once and for all. In economics that is not the case, and to convert a model into a quantitative formula is to destroy its usefulness as an instrument of thought. Tinbergen endeavours to work out the variable quantities in a particular case, or perhaps in the average of several particular cases, and he then suggests that the quantitative formula so

\footnotetext{
${ }^{8}$ Some economists have used words like natural unemployment which is somewhat mystifying and also a bit absurd.

${ }^{9}$ Navarro \& Soto (2006), Procyclical Productivity in Manufacturing. Cuadernos de Economia, Vol. 43 (Mayo), pp. 193-220.
} 
obtained has general validity. Yet in fact, by filling in figures, which one can be quite sure will not apply next time, so far from increasing the value of his instrument, he has destroyed it. All the statisticians tend that way. Colin, for example, has recently persuaded himself that the propensity to consume in terms of money is constant at all phases of the credit cycle. He works out a figure for it and proposes to predict by using the result, regardless of the fact that his own investigations clearly show that it is not constant, in addition to the strong a priori reasons for regarding it as most unlikely that it can be so.

Figure 3 presents a rather ugly perspective from a market point of view. The markets will not have any kind of equilibrating intrinsic forces which affect unemployment in a positive direction mostly since this would require a homogenous labour force. Both Hume and Ricardo discuss these matters, but in the neoclassical theory, which deals with a sort of medieval village economy based on barter, the difficulties well-known to economists in the 18th century never occur theoretically and cannot do so. ${ }^{10}$

From the point of view of inflation-policy the development described will increase the sensitivity of inflation with respect to demand variations the effects of which on total inflation rate may vary. If the approach to inflation remains focused on supply demand conditions particularly with respect to the issue of real investments this increase in sensitivity will not have any more dramatic effects but if the focus changes towards financial factors and particularly the valuation aspects in conjunction with dramatically increased cross-border flows, we will approach a different world with respect to policy formation more about this below.

\section{Inflation, Prices, and Measurement}

The modern market economy is a money economy. We do not purchase commodities in a barter system.

Money is an anomaly in the neoclassical economy. The price vector is a unique measure of a specific equilibrium in an ordered Euclidian space, which may allude to prices/money but it has not anything with prices/money in ordinary business to do. Keynes discusses "primitive stone money of Polynesia" in the beginning of Treatise of Money (1930, p. 14) which is a better allusion to money.

The price vector of the neoclassical equilibrium measures the precise optimizing exchange relations for one and only one precise general equilibrium, and to each kind of possible combination of $\left(\Im_{i}, e_{i}\right)$ there exists one unique equilibrium. Subsequently we have infinite different optimal price vectors in the economy. Furthermore, the different possible equilibria are not connected, but nowhere dense, remembering that the neoclassical equilibrium theory concerns relative prices given the preference functions, incomes, and income distribution of each and all the individuals. Interpreting such an equilibrium inter-temporally we should lock the income distribution and the preference distribution for ever. Furthermore, the dimensionality of the commodity space must be constant forever. Such assumptions are implicit in the fundamental axioms of the neoclassical general equilibrium theory and imply that there is no alternative to a specific general equilibrium. The acquired general equilibrium has no environment and consequently there does not exist any kind of convergence processes to equilibrium, either you are in equilibrium or not and if you are not then you must exclude the very existence of a general equilibrium. ${ }^{11}$

Consequently, it is hard to interpret the general equilibrium price vector in what is understood as prices in everyday business. This was already pointed out by Jean Baptiste Say, who has wrongly been interpreted as an equilibrium theorist:

${ }^{10}$ In Ekstedt \& Fusari (2010), Ekstedt (2012) and Ekstedt (2015) the theoretical insufficiencies of the neoclassical theory and also the Keynesian theory are extensively discussed, also other aspects of disequilibrium economies are discussed working in the same direction as our more stylized discussion of the historical development above.

11 This is analysed in depth from different aspects in Ekstedt \& Fusari (2010, ch. 2), Ekstedt (2012, ch. 3) and Ekstedt (2015, ch. $1)$. 
When I am told that the great pyramid of Ghaize is 656 feet square at the base, I can measure a space of 656 feet square at Paris or elsewhere, and form an exact notion of the space the pyramid will cover; but when I am told that a camel is at Cairo worth 50 sequins, that is to say, about 90 ounces of silver, or 100 dollars in coin, I can form no precise notion of the value of the camel; because, although I may have every reason to believe that 100 dollars are worth less at Paris than at Cairo, I can not tell what may be the difference of value. (Say, 1834 [1803], p. 247)

And he states:

Money or specie has with more plausibility, but in reality with no better ground for truth, been pronounced to be a measure of value. Value may be estimated in the way of price; but it can not be measured, that is to say, compared with a known and invariable measure of intensity, for no such measure has yet been discovered. (Say, 1834 [1803], p. 246)

What can be said is that Jean Baptiste Say in the early 19th century had a better understanding of measure theory in the physical reality than is produced in the interpretation of general equilibrium theory as something which can guide the analysis of the real world.

In the economic reality, there is nothing but local and temporal equilibria mostly of a dissipative nature. This is however not to be confused with stability and predictability in a social sense, but such stability is created by social, cultural, demographic, ethical, and economic factors, just to mention a few.

\section{The Atomistic Trap and the Mysterious Money}

The construction of the neoclassical theory in its current form which builds on an explicit axiomatic structure is from the point of view of empirical sciences curious, not to say bizarre. The fundamental axioms transform the commodity space to an ordered Euclidian space and consequently transform the agent into commodity vector, Debreu (1982) defines an agent: $\left(\succsim_{i}, e_{i}\right)$, a preference relation and an initial endowment vector. This implies that all variables are transformed to atomic variables, which have no content except a numerical point in a Cartesian space. Consequently the commodities will and must not have any structural relationships whatsoever. That means that liberated from any structural restrictions the general equilibrium is true for any set of atomic variables. Furthermore the commodity space as well as the utility space is only defined in the positive orthant. All this is very convenient for mathematical treatment, in using rather simple mathematics for real numbers on a continuous and convex space and additive aggregation is allowed so it is easy to sum individual optima to a society optimum.

To squeeze in the socio-economic reality in such a model is however a bit adventurous, since commodities and agents are to be seen as complex variables, which rejects the axiom of reflexivity: a commodity is identical to itself, is the key axiom in this transformation. This axiom implies that a commodity is only demanded with respect to its physical specification not with respect to the service it implies to the customer. ${ }^{12}$

The problems which the neoclassical theory has with explaining the money concept as used in everyday business come simply from the fact that money per definition is an atomic variable. Thus when we have already transformed all commodities and agents to atomic variables why should we need another atomic variable. Prices in neoclassical theory are relative prices so what are money prices?

Thus, money as a scientific concept is rather mysterious since it works quite well in ordinary life, and moreover it works for a disequilibrium economy. If commodities have structural relationships in the eyes of the consumer, which means that commodities are consumed not as physical items per se but with respect to their

${ }^{12}$ This axiom is implicitly rejected by Arrow's paradox (Ekstedt 2012, ch. 3) and by the modern consumer theory built on Gary Becker's household production theory. 
role in the demand structure of a particular consumer and furthermore we will not achieve a unique price vector for the economy. This will imply that while accepting the microscopic studies of a commodity under assumption of social inertia, additive aggregation must be rejected. Subsequently there is no relation between individual and social optima.

In Ekstedt (2012, ch. 3) the following proposition is shown with respect to a barter economy, where we accept commodities as complex variables:

\section{Proposition I:}

Assume a system $A^{*}$ consisting of a finite number of subsystems, which are to be regarded as proper classes, $\mathrm{s}_{1} \ldots \mathrm{s}_{\mathrm{n}}$. If then we have a measure allowing us to define an optimizing rule both on $A^{*}$ as well as $s_{1} \ldots s_{n}$; optimization of the global system $\mathrm{A}^{*}$ must imply that at least one of the subsystems $\mathrm{s}_{\mathrm{i}}$ must sub-optimize.

If on the other hand all the subsystems, $\mathrm{s}_{1} \ldots \mathrm{s}_{\mathrm{n}}$ are optimized according to the same optimizing process the global system A* must sub-optimize. (Ekstedt, 2012, p. 83)

However, when analysing a money economy which implicitly rejects the existence of general equilibrium, money prices become relevant as measures only locally and temporally. In such a state, comparing with a barter economy, there does not exist anything but at best local and temporal equilibria and these are dependent on social and cultural inertia.

But with respect to a money economy where commodities are valued in money prices, Proposition I has no logical meaning. It is shown in Ekstedt (2015, ch. 3):

\section{Proposition II:}

With respect to a real analysis equivalent to barter, the Proposition I hold.

When we pass over to a non-equilibrium analysis where goals and restrictions are formulated in monetary terms we lose all logical relations to the real economy and consequently Proposition I has no meaning.

Thus, something happens when entering an economic analysis in money terms. The basic reason is that money and real commodities as concepts belong to different logical categories. Money is defined in an atomistic way while commodities belong to complexes. ${ }^{13}$ Much of the analytical philosophy during the 19th century in the aftermath of Principia Mathematica dealt with the question of atomistic and complex facts and Russell's paradox ultimately ending in Gödel's paradox led to the important result that mathematical analysis should be based on atomic facts to achieve uniquely and consistent derivations. Thus, the axiomatic structure of the neoclassical theory is equivalent to a definition of an ordered Euclidian space based on atomic variables without any real content and structures. Thus, commodities belong to complex variables but money belongs to atomic facts. This explains the difference between the two propositions above.

Of fundamental importance to understand the difference between the neoclassical approach and Keynes' philosophical foundation is the fact that Keynes was a key discussant in the philosophical debate on complex and atomic facts with his "Treatise on Probability" (Keynes, 1962 [1921]). Furthermore the neoclassical theory is basically built on additive aggregation, which was rejected by Keynes in a speech to the Apostles 1903 (information from Lord Robert Skidelsky, quoted in Ekstedt, 2015, p. 50).

Considering this, there is no possibility to create any form of compromise between Keynes' thinking and theory ending in a general equilibrium defined in the neoclassical way.

13 The most important feature is then that for atomistic concepts the universal class for the sets of a concept belongs to itself while this is not the case for complexes. 
General equilibrium in its axiomatic form is nowhere dense which implies that no convergence processes exist, since the equilibria have no environment. Therefore, Walras discussed two converging processes: the auctioneer and the tatonnement processes. During these convergent processes, no exchange takes place since we then have the case of false trading. When we enter the more precisely expressed axiomatic structure of the Arrow-Debreu setting this is fundamental since an axiomatic structure always defines a set which is nowhere dense, either you are in the defined structure or you are not; it has no environment, consequently it is impossible even to think of a set of different states of general equilibrium and mathematically describe a converging process during which economic exchange can take place.

In Keynesian or other disequilibrium approaches the analysis is based on money values and manipulated money values. ${ }^{14}$ Often Keynesian models make some money market arrangements for money but we seldom see the concept of money discussed. Furthermore, the dimensionality problem, essential with respect to all form of price indexing, is even more seldom discussed although Keynes noted that problem (1936 [1983], p. xxxv). Thus, economic growth very seldom only has a pure quantitative effect and an introduced commodity is seldom a pure substitute for another. Economic growth generally implies new commodity dimensions and changed structural relationships between existing commodities.

It is with respect to price indices the dimensionality of the commodity basket becomes a sensitive issue. In Ekstedt (2015, pp. 131-134) it is shown how a change in the dimensionality affects the prices. A period of growth in the number of commodity dimensions will if it is not explicitly accounted for in the inflation indices appear as increased inflation and subsequently a strict anti-inflation policy in such a case leads to deflation in real terms.

\section{Money and the Quantity Identity}

The two propositions coexist since the concept of real growth builds on nominal prices and the manipulation of these. Since the underlying theory of price indices refers mostly to the neoclassical theory, as the most formalized theory, where the dimensionality of the commodity basket is constant, we arrive at the conclusion that these inflation indices are meaningful for the real economy if we are in a general equilibrium, if not, there is a theoretical mismatch where no conclusions can be drawn scientifically. ${ }^{15}$

Consequently, when we pass over to the Quantity Identity;

$$
M \cdot V \equiv P \cdot Y
$$

The very definition of variables will set the possibilities of making some consistent theories. In the light of above discussions ending in the rejection of general equilibrium, there are problems with respect to the variable definitions.

If the concept of money, $\mathrm{M}$, is fully controlled by some agent(s) the precise quantity is then obviously known, $\mathrm{M}$ to be hold constant or be varied at the pleasure of the authorities. If, however there are other papers or items which could be used as money and which is regarded as almost as liquid as the items defined in $\mathrm{M}$ and which furthermore is outside the authorities' control then $\mathrm{M}$ should be handled like a partly endogenous variable.

\footnotetext{
${ }^{14}$ So called quantitative development of GDP for example is based on nominal prices corrected by an inflation index which is a relation between nominal prices of a basket at two different times. The technique builds on assumptions from neoclassical theory.

15 If the dimensionality varies we are not able to use standard mathematics since we leave a constant Euclidian space. This follows from Brower's dimensional invariance theorem.
} 
When it comes to the velocity of money, $\mathrm{V}$, this is set by social and economic structures and patterns, but to define it as an exogenous parameter implies that $\mathrm{M}$ is fully controlled.

Since general equilibrium is rejected there is no well-defined $\mathrm{P}$. Thus in the above identity variations of the left hand side, given the price indexes used, most will cause structural changes in the price structure and this most probably implies that $\mathrm{Y}$ will not be clearly defined. Thus in a temporal setting $\mathrm{Y}$ and $\mathrm{P}$ are sets defined simultaneously given certain assumptions, which are ok in general equilibrium but since this is rejected it is impossible to distinguish between $\mathrm{Y}$ and $\mathrm{P} .{ }^{16}$

The identity is always true if the contained variables are empirically undefined and general equilibrium is assumed; the Quantity Equation actually remains to be an identity since prices are exact relative prices, the base of which can be any natural number. $\mathrm{Y}$ is real commodities and has no relation to what is called prices. $\mathrm{M}$ can be a set of any countable items; small flat white stones will do perfectly well. However, when regarding velocity, $\mathrm{V}$, it is a bit curious, since once the price vector is fixed the whole money story is over and out and there is actually no need for money any more, since an intertemporal general equilibrium obviously requires perfect future markets; some approximations of the market result with following convergence will not do since general equilibrium in the axiomatic sense is nowhere dense.

Thus assuming that it is fully understood what money, $\mathrm{M}$, is and how money can be used, and furthermore a priori assumptions are taken with respect to velocity variable $\mathrm{V}$ it is easy to realize that changes in $\mathrm{M}$ will affect prices, $\mathrm{P}$, and the real production, $\mathrm{Y}$, in some way. There is no problem to accept this. The problem is about saying more, for example in which way the changes in $\mathrm{M}$ will affect $\mathrm{P}$ and $\mathrm{Y}$. Assuming that the economy is in some kind of equilibrium; it is hard to escape the problem of money illusion. If no money illusion is assumed, then it is hard to see any point with the whole exercise.

Consequently, accepting that our daily economy is a disequilibrium economy implies that changes in $\mathrm{M}$ will affect the relative prices and then the analysis grows into something much more intricate, ultimately dealing with structural matters.

\section{Monetarism and Real Bill Approach}

Late 20th century discussions on monetary matters have mostly concerned the Quantity Equation and the supply of money. It has also concerned the link between the supply of money and the inflation.

The central banks in Europe ran an almost absurd anti-inflation policy for some 15 years and explained that low inflation stimulates growth and we witnessed a grim austerity policy.

Lately when the central banks run into the realm of negative interest rates, some spokesmen explained some idea of a reversed relationship between money supply/interest rates and inflation and thus that inflation will increase growth. Thus we have witnessed a 180 degrees change in beliefs from the idea that, which we were told earlier. Politics - yes perhaps but it unfortunately also gives some relevance to Keynes' words that practical men in power "are distilling their frenzy from some academic scribbler of a few years back" (Keynes, 1936 [1973], p. 383).

Going back to the so called Bullionist debate in the early 19th century Monetarism as we know it was an alternative in the debate and, the ultimate winner as it appeared in the Bank Charter Act 1844, which was leaning on Ricardo's Ingot Plan posthumously publish 1826. Ricardo was one of the more dogmatic bullionists,

\footnotetext{
16 These aspects are discussed more comprehensively in Ekstedt (2015, ch. 3).
} 
while Henry Thornton (1939 [1902]), who actually made the basic studies and who in the end supported the coming solution was not dogmatic but saw it more as a structural problem. Adam Smith for example was very far from monetarism and claimed the so called Real Bill approach, which implies that paper money has a one to one relationship with the stock of precious metals, fundamentally gold.

Monetarists often claim that Hume, the Dominican Friars of Salamanca were monetarists, which is completely historically wrong. It is true that they recognized that excess supply of the medium of exchange per se could create inflation but that was only one aspect of inflation. ${ }^{17}$

The bullionist debate was ignited by excess supply of paper credits with respect to available stock of precious metals; this occurred during the Napoleonic wars so it was hardly surprising. In effect it was similar to the 2008 debacle when banks expanded credits due to the lax policy of emitting bonds. Thus the security of the outstanding debts in principle vanished.

There are basically three well-known characteristics of money which give rise to intrinsic contradictions in the very concept, money as a medium of exchange, money as liquidity, and money as an accounting measure with respect to, historical current and future, values of assets/liabilities. According to the neoclassical theory these aspects are unproblematic in an eternal general equilibrium with no contradictive environment.

In the real world where there are only local and temporal equilibria these characteristics become contradictory. Thus with respect to the fundamental aspect of money as medium of exchange, changing the volume in circulation and the speed of circulation will surely affect the economic turnover.

Consequently, the quantity identity $M \cdot V \equiv P \cdot Y$ is indeed an identity, however when this is transferred to a quantity theory, we define the involved variables in a certain way, and must also assume an institutional structure where the definitions are adequate. Thus we could say that to talk about a Quantity Theory as we know it from current monetary theory requires that certain structural conditions are fulfilled. David Hume for example, as well as the Dominican friars of Salamanca in the 16th/17th centuries, has been called quantitative theorists although they only discussed the quantity identity with respect to a singular increase in the medium of exchange. ${ }^{18}$ This is also the case when we read the two contemporary theorists of the money economy, Henry Thornton (1802) and Jean Baptiste Say (1803), neither of them was a quantity theorist nor an equilibrium theorist $^{19}$.

The Swedish economist Knut Wicksell commented upon the discussions on banking school (real bill) and currency school (bullionism/quantity theory) some 120 years ago:

I already had my suspicions - which were strengthened by a more thorough study of the writings of Tooke and his followers - that, as an alternative to the Quantity Theory, there is no complete and coherent theory of money. If the Quantity Theory is false - or to the extent it is false - there is so far available only one false theory of money and no true theory. (Wicksell, 1936 [1893], p. xxiii)

Tooke was a proponent of the Banking School.

The best explanation for the inability to present a single and consistent theory of money is that we actually find in Henry Thornton's (1802) work on Paper Credits in Britain. He distinguishes between papers with enforced circulation, which are law money, and papers capable of circulation. The former one is ordinary law money but the second one might be any kind of security, during Adam Smith's times, when the Real Bill

\footnotetext{
17 In Ekstedt (2012, ch. 2) these things are discussed.

18 Hume also discusses the role of money from a social and cultural point of view, which indeed is interesting.

19 Ekstedt (2012, ch. 2) discusses both of them and their contributions.
} 
approach was the reigning dogma, it was normally thought of as gold but Henry Thornton enlarged it to in principle any kind of security used in business transactions.

Henry Thornton's point is that while the law money has a given supply and circulates in all groups of agents, papers which are not law money but have the ability of circulation vary in "supply" as a mean of exchange and are also asymmetric with respect to different groups of agents.

Figures 4 and 5 are illustrations of the basic forms of the two systems. Normally in our times, elements from both systems coexist but we will discuss the systems as in isolation.

Figure 4 illustrates the pure monetarist model.

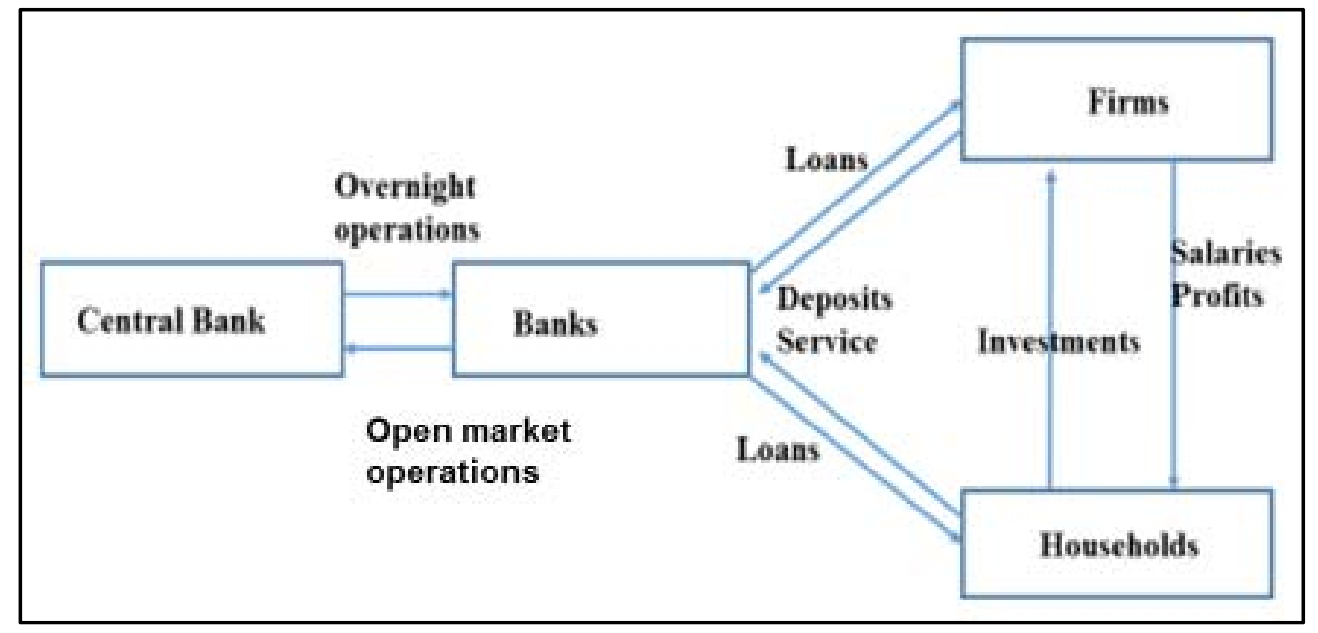

Figure 4. Monetarism/currency school.

Due to its control of the law money, medium of exchange, it also follows that assets which could be used as next to money will be under almost total control.

This will mean that money is a control variable and might be set to any value $\bar{M}$. This implies from the quantity identity that we will have $\bar{M}=\frac{P \cdot Y}{V}$ : whether or not the velocity, $\mathrm{V}$, which is constant, is of minor importance by now, but if one assumes that the way price changes over time is measured can be assumed to be consistent we will have a separation between $\mathrm{P}$ and $\mathrm{Y}$ and consequently $\mathrm{V}$ will appear as a residual and solved endogenously. However, if there is some doubt of the possibility of separating $\mathrm{P}$ and $\mathrm{Y}$, there are nominal values but it is difficult to judge the dimensionality of the commodity space, which will also affect the judgement of velocity of money. But since virtually all assets which can be used as medium of exchange are controlled we might be rather safe in assuming at least that we may have some knowledge of the $\frac{d V}{d t}$ in the short run.

Figure 5 illustrates the Real Bill/Banking School principles. During the days of Ricardo the prime security was gold. Thus the criticism of Ricardo and Henry Thornton was that the banks expanded the paper credits beyond its coverage in gold. This led to liquidity crises due to hoarding in gold-guineas.

In a way it started in 1793 when there was a severe liquidity crisis, in London City, due to shortage of Bank of England paper notes which were all covered by gold and were used in business transactions. Thornton writes (1802 [1939], pp. 97-98): 


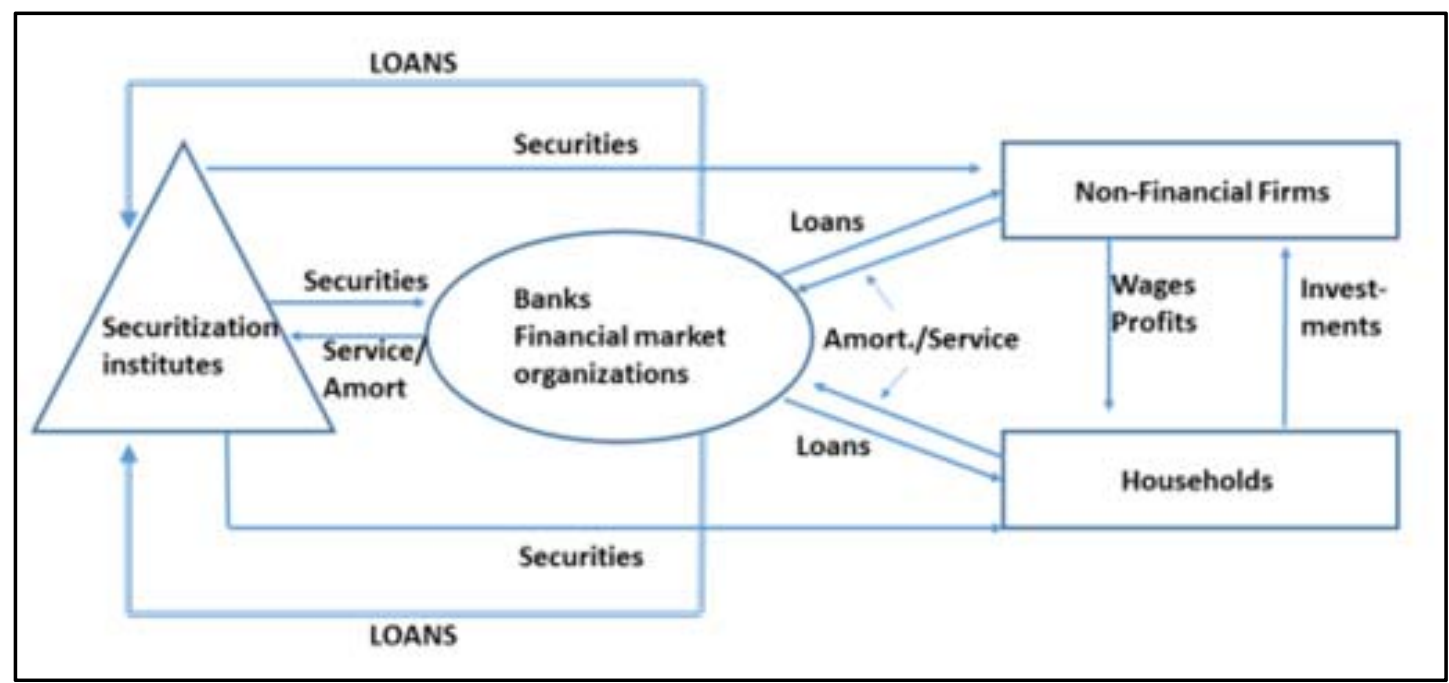

Figure 5. Real bill system.

The alarm, the first material one of the kind which had for a long time happened, was extremely great. It does not appear that the Bank of England notes, at that time in circulation, were fewer than usual. It is certain, however, that the existing number became, at the period of apprehension, insufficient for giving punctuality to the payments of the metropolis; and it is not to be doubted, that the insufficiency must have arisen, in some measure, from that slowness in the circulation of notes, naturally attending an alarm, which has been just described. Every one fearing lest he should not have his notes ready when the day of payment should come, would endeavor to provide himself with them somewhat beforehand. A few merchants, from a natural though hurtful timidity, would keep in their own hands some of those notes, which, in other times, they would have lodged with their bankers; and the effect would be, to cause the same quantity of bank paper to transact fewer payments, or, in other words, to lessen the rapidity of the circulation of notes on the whole, and thus to increase the number of notes wanted.

The circulation of guineas and the papers directly linked to it decreased and were actually hoarded by country banks while in London it led to a decrease in liquidity which threatened the punctuality of commercial payment, and Thornton proceeds:

Gold, in such case, would unquestionably be hoarded through the great consternation which would be excited; and it would, probably, not again appear until confidence should be restored by the previous introduction of some additional or some new paper circulation. (ibid., p. 114)

Figures 4 and 5 illustrate the pure principles of the system although we have modernized the Real Bill system to allow for non-gold securities, which are accepted at the pleasure of the market, at the incurrence of some acceptable risk.

Thornton describes the difference between money based on law and money capable of circulation in his critiques of Adam Smith's version of the real bill principle, basically concerning the circulation of money/papers/securities:

The error of Dr. Smith, then, is this:- he represents the whole paper, which can easily circulate when there are no guineas, to be the same in quantity with the guineas which would circulate if there were no paper; whereas, it is the quantity not of "the thing which circulates," that is, of the thing which is capable of circulation, but of the actual circulation which should rather be spoken of as the same in both cases. The quantity of circulating paper, that is, of paper capable of circulation, may be great, and yet the quantity of actual circulation may be small, or vice versa. The same note may either effect ten payments in one day, or one payment in ten days; and one note, therefore, will effect the same payments in the one case, which it would require a hundred notes to effect in the other. 
I have spoken of the different degrees of rapidity in the circulation of different kinds of paper, and of the consequent difference of the quantity of each which is wanted in order to effect the same payments. I shall speak next of the different degrees of rapidity in the circulation of the same mediums at different times: and, first, of bank notes. (ibid., p. 96)

The quotes from Thornton are extremely important since it draws an analytical border between two types of medium of exchange. The law money is accessible for all agents and granted by official authorities and with a risk factor approaching zero, but the papers which are capable of circulation are mostly used in business transactions and have no official grants other than a degree of expected risk, which is basically set by the agents themselves in conjunction with general open information.

The latter form of medium of exchange varies according to the activities in the economy in question. As long as the economy is closed in conjunction with high control of money supply, the papers capable of circulation are of minor importance with respect to the quantity identity but if the economy becomes open to international markets the market papers capable of circulation will play a more and more important role.

Consequently, which one of the Figures of 4 and 5 that will dominate the financial transactions will depend upon structural conditions of the analysed economy not upon some theoretical law, the quantity identity will thus be possible to transform to a theory like the Monetary Theory if there is a closed economy with substantial official control of the money supply and the financial market.

Looking at the difference between Figures 4 and 5 the great change in the role of the banks is immediately seen. In Figure 4 the profits of the banks will be the gap between interest on lending and borrowing. Since the lending in practise is set by the law with respect to deposits and own capital the stock of assets and liabilities are relatively inert and thus the interest rate difference will also be inert when the interest rate is basically controlled by the authorities, money supply and/or open market operations.

In Figure 5 the banks have a completely different role. In the extreme case the banks are nothing but a mediator of loans. Thus in principle they take a mediating fee based on a fraction of the loan, amortizations, and interest payments. The incentive for the banks is to get the lending as big as possible given the appetite of the market for new bonds. The risk aspect is not falling within the interest of the bank with respect to short and even medium term considerations but is only concerning the macroscopic risk for the whole system. The securitization institute has some interest to control the individual risks for the set of loans which are the basis for emitting new bonds/bills. The agents, who have the greatest direct interest in controlling the individual risks, are the very market agents issuing and buying the bond/bill. Thus the real transaction given a well-defined supply and demand situation is between the borrower and the buyer of the bonds. But these are anonymous to each other, so the authorities can set a law that the banks shall have this risk control under a threat of more or less severe measures. Since the bank has to base their judgements on rather conventional rules this will imply that checking the current/recent inflow of incomes in relation to the outstanding debt will be a rather normal procedure, while market priced assets are more difficult to take into consideration. Furthermore, to judge the potential risks and values of production venture by small entrepreneurs is virtually impossible since the time profiles of these are different from the short-run accounting valuation. With respect to the Currency School in Figure 4 the profits of the banks by its very structural configuration is more inert and a conscious mixture of entrepreneurial ventures gives a possibility for lending to edge-cutting ventures. An entrepreneur in the realm of a Banking School system is more or less left with the alternative to exchange control of the venture for getting financial resources. It is of course possible with respect to Figure 5 to think of small regional banks relatively isolated as Sargent and Wallace (1982) do when they analyse the respective system from a general 
equilibrium point of view. As Laidler (1984) points out the authors then squeeze in the system into a theoretical structure which make them forced to make changes in what was seen as the real bill approach.

A problem during the end of the 18th century was the guinea hoarding of which the quote above from Thornton shows the effects. ${ }^{20}$ The hoarding was triggered by the structural instabilities caused by the Napoleonic wars and this is important because a monetary system must work even under situations of economic instability; it shall in any case not cause economic instability.

What we must remember is that in our case there is no deliberate creation of a new financial system but an organic development because of the globalization and the international mergers and acquisitions creating huge industrial/financial conglomerates. The debate at the 1980s and 1990s, Sargent and Wallace (1982), Laidler (1984), Thomas Cunningham (1992), and Michael Sproul (2000) mostly concerned the superiority of one or the other of the system starting from a general economic setting, which David Laidler opposed. The ethical side of the problem was discussed by Sproul (2000) in an attack on Henry Thornton. The central point was the risk analysis and issuance of bonds/bills. But the thing is that discussing an organic development we may of course discuss the ethical problems but in this case the agents are facing an actual newly developing world which they must master. Thus, the basic structure is changing. The lending banks make a conventional judgement but this judgement is only local and temporal and when a bond is issued it has its maturity and what happens with the security over time is virtually impossible to estimate other than in very crude probability terms. It is true that the debacle 2008 was based on slippery judgements and slippery control, but the control system of a system like in Figure 5 is indeed a problem. You should lay the responsibility on banks which has no real interest in the valuation; thus, the control system is effectuated by those who have the least interest in it since it implicitly is against its profit incentives. Of course, one can moralize but first we should understand the anomaly and the basis for Sproul's accusation of Thornton of moralizing is not found in what Thornton has written but in the difference in research approach. Thornton analyses the actual market behaviour, where he himself is an actor, while Sproul starts from a normative general equilibrium approach where the almighty invisible hand guides markets.

Thus, if it is possible to control the volume of law money and subsequently the outstanding bonds/bills at the financial market we must agree that the quantity identity might be transformed to a theory. The only problem is that the methods used for measuring inflation are logically bound to imply a constant dimensionality of the commodity space. If not, we will end up in a juxtaposition of inflation and growth through changes in dimensionality, though a short run measurement in a relatively inert economy will give reasonably reliable results. However, listening to media reporting fractions of per cent as worthy of mentioning seems ridiculous.

However, accepting the banking school (real bill) as the leading principle ends up in a system where those actors, generally banks, who have the responsibility of control have no intrinsic interest in applying the control measures. Furthermore, the public control is only indirect and lies in creating rules. A Central Bank has little or no effect on the markets except for the role as the "lender of last resort" but that role is weakened by the globalization.

\footnotetext{
${ }^{20}$ Ricardo answered an article in Morning Chronicle by Charles Bosenquet that the issue of paper money from the Bank of England under the Real Bill regime would transfer Bank of England to a gold mine and that we would revive the days of the inflow of gold from America. Correspondence of David Ricardo, Vol. 3 Pamphlets and Papers 1809-1811 [1809]. http://oll.libertyfund.org/titles/204.
} 
Inflation whatever it is and how it is defined is a central variable for expectations of future values since it is the central variable in the discounting. Thus, eventual effects of inflation on production and demand are insignificant as long as the economy is in the realm of one digit rates, but with respect to the financial side even fractions of percent counts. Thus, with respect to the global financial markets inflation expectations concerning values of assets and liabilities are so strong that those theoretical doubts raised with respect to inflation measurement are of minor, not to say zero, significance.

But this sharpens the intrinsic conflict of money and the two roles of being a medium of exchange and an accounting measure with respect to history, now and future.

Changes in inflation let us say in the interval of \pm 2 percent probably is well in the realm of measurement uncertainty in relation to real growth, but still it can be expected that it will have a considerable importance in the expected values of future assets and liabilities; this raises the question of the future value of a debt from a macroscopic point of view. Is perhaps saving a nominal value at the price of growth the central point? In that case, exaggerating a bit, what shall we eat and who shall eat in the future? This question is an entrance to the problem of social stability.

Finally, the banking school/real bill system will in the end probably be negative for new entrepreneurs and smaller companies with small securities to back up the ventures. This is not as much due to banks or financial companies but most probably an effect of control systems securing for macroscopic risks.

\section{Final Comments}

The reason for this kind of market development from Figures 4 and 5 and the different role of inflation are to be searched in the development of the economic structure in the aftermath of WW2. The problem of inflation was linked to the Bretton Woods system and the necessity of balancing trade to have a stable system. After the break-down of Bretton Woods we had a period when many countries formed different kind of policy, multilateral, bilateral as well as unilateral in form of currency baskets. Such a policy led to the same attitude to inflation as before.

However, in the 1970s/80s when markets became more globalized practical reasons made companies raise money on the very place of investments which mainly followed the demand structure, as the internationalization proceeded differences in taxes, labour market rules, laws affecting production and so on came to direct the real investment flows, and thus the corresponding money flows. During 1980s-90s the efforts by the states to make the international financial flows more smooth and secure, released the financial flows from the real flows. This was also accompanied by decisions by Bank of England and Federal Reserve, other central banks following, to accept the banks' market valuations and rely on controlling the soundness of the valuation principles.

All this implied a refinement of the "financial engineering" and we arrived at an international system where the banking/financial sector was actually defining the concept of money with respect to what Thornton calls "paper capable of circulation".

The inflation problem is to be seen in this perspective. Inflation differences and more precisely inflation expectation differences will now directly affect the valuation of securities and as we see from Figure 5 this will primarily not affect only the banks but the whole body of assets and liabilities irrespective of holders. Thus, the money system and monetary policy is, with respect to Figure 5, in principle endogenous to the real transactions and it is here that the imprecision of the inflation concept hits the economy. 
It is rather bizarre to see that the attitudes to the problem of inflation and growth have changed 180 degrees, low inflation as a grant for high growth has been changed to increasing inflation to foster growth. The intrinsic uncertainty of the relations between growth and inflation was in fact already discussed by David Hume. It disappeared in the neoclassical model since money as a realistic concept disappeared, and was revived by Keynes but disappeared again in the IS-LM model only to appear as something called stagflation which was invented as an answer to irregularities of the Phillips-curve which was nothing but a crude statistical relationship where concepts were not even defined in a statistical sense.

The analysis has now arrived at a nasty question for economic policy: Are we to protect the future value of paper assets and liabilities at the expense of real growth?

If the answer is yes to that question: what and who is protected? In fact, then the financial wealth is protected at the price of a shrinking production system and it is then also created a process of unlimited concentration of economic wealth. Whether this is socially/culturally/ethically sustainable others may answer.

\section{References}

Aristole. (1990 [original around 334-324 BC]). Politics Bno. (1257 $)$ in The Works of Aristotle vol. II, Encyclopædia Britannica,

Inc. Chicago, London, 452, Bno. $1258^{\mathrm{b}}$ (Bno refers to the Berlin enumeration).

Arrow, K. J. (1986). Rationality of self and others in an economic system. The Journal of Business, 59(4): Part 2: The Behavioural Foundations of Economic Theory, (Oct.), S385-S399.

Arrow, K. J., \& Hahn, F. H. (1971). General competitive analysis. San Francisco: Holden Day Inc.

Boltho, A. (1982). Growth. In A. Boltho (Ed.), The European economy: Growth and crises (pp. 9-37). Oxford: Oxford University Press.

Brody, T. (1993). The philosophy behind physics. Berlin, Heidelberg, New York: Springer Verlag.

Cunningham, T. J. (1992). Some real evidence on the real bills doctrine versus the quantity theory, economic inquiry. Western Economic Association International, 30(2), 371-383.

Debreu, G. (1959 [1987]). Theory of value. New York: Wiley.

Debreu, G. (1982). Existence of general equilibrium. In Handbook of mathematical economics. vol. II ed. K. J. Arrow \& M. D. Intrilligator. Amsterdam/New York: North-Holland Publishing Company.

Eichengreen, B. E. (1995). Europe's Post-War Recovery. Cambridge, Cambridge University Press.

Ekstedt, H., \& Westberg, L. (1991). Dynamic models for the inter-relations of real and financial growth. London: Chapman \& Hall.

Ekstedt, H., \& Fusari, A. (2010). Economic theory and social change: Problems and revisions. London and New York: Routledge.

Ekstedt, H. (2012). Money in economic theory. London and New York: Routledge.

Ekstedt, H. (2015). Money, valuation and growth: Conceptualizations and contradictions of the money economy. London and New York: Routledge.

Georgescu-Roegen, N. (Aug. 1936). The pure theory of consumer behaviour. The Quarterly Journal of Economics, 50(4), 545-593.

Grice-Hutchinson, M. (1952). The School of Salamanca. Oxford: Clarendon Press.

Hicks, J. R. (1937). Mr. Keynes and the classics—A suggested interpretation. Econometrica, 5(April), 147-159.

Hicks, J. R. (1980-1981). IS-LM: An explanation. Journal of Post Keynesian Economics, 3, 139-155.

Hume, D. (1770 [1752]). Essays and treatises on several subjects, vol. II, containing essays, moral, political, and literary. Printed for T. Cadell (successor of Mr. Millar) in the Strand; and A. Kincaid and A. Donaldson, at Edinburgh.

Jevons, W. S. (1888 [1871]). The theory of political economy. London: Macmillan \& Co. Available at: http://www.econlib.org/library/YPDBooks/Jevons/jvnPE3.html\#

Keynes, J. M. (1930 [1953]). A treatise of money. London: Macmillan \& Co.

Keynes, J. M. (1973 [1936]). The general theory of employment interest and money. Cambridge: MacMillan, Cambridge University Press.

Laidler, D. (1984). Misconceptions about the real-bills doctrine: A comment [The real-bills doctrine versus the quantity theory: A 
reconsideration]. Journal of Political Economy, 92(1), 149-155.

Lundberg, E., Ohlin, G., \& Werin, L. (1975). Time for growth? Macroeconomic policy board report 1975-76. Stockholm: Studieförbundet Näringsliv och Samhälle (SNS).

Makarov, V. L., \& Rubinov, A. M. (1977). Economic dynamics and equilibria. Heidelberg, Berlin: Springer Verlag.

Mantel, R. (1974). On the characterization of aggregate excess demand. Journal of Economic Theory, 7, 348-353.

McFadden, D., Mas-Colell, A., Mantel, R., \& Richter, M. K. (1974). A characterization of community excess demand functions. Journal of Economic Theory, 9(4), 361-374.

Mill, J. S. (1990 [1863]). Utilitarianism, in Great Books of the Western World no. 40. Chicago, London, New Delhi, Paris, Seoul, Taipei, Tokyo: Encyclopædia Britannica, Inc.

Navarro, L., \& Soto, R. (2006). Procyclical productivity in manufacturing. Cuadernos de Economia, 43(Mayo), 193-220.

Rizvi Abu Turab, S. (2006). The Sonnenschein-Mantel-Debreu Results after Thirty Years, History of Political Economy 38 (annual suppl.)

Russell, B. (1924 [2007]). Logic and knowledge. Nottingham: Spokesman.

Samuelson, P. (1948). Consumption theory in terms of revealed preference. Economica, XV, 243-253.

Sargent, T. J., \& Wallace, N. (1982). The real-bills doctrine versus the quantity theory: A reconsideration. The Journal of Political Economy, 90(6), 1212-1236.

Say, J. B. (1834 [1803]). A treatise on political economy; or the production, distribution, and consumption of wealth. Philadelphia: Grigg \& Elliot, 9, North Fourt Street.

Sonnenschein, H. (1972). Market excess demand functions. Econometrica, 40(3), 549-563.

Sproul, M. F. (2000). Three false critiques of the real bills doctrine. Department of Economics, California State University, Northridge. http://www.csun.edu/ hceco008/critique.htm

Thornton, H. (1939 [1802]). An enquiry into the nature and effects of the paper credit of Great Britain. London: George Allen \& Unwin.

Available free

at

http://oll.libertyfund.org/index.php?option=com_staticxt\&staticfile=show.php\%3Ftitle=2041\&layout=html

Thompson, D’Arcy W. (1942 [1992]). On growth and form. Cambridge: Cambridge University Press.

Weisstein, E. W. (1999). CRC concise encyclopedia of mathematics. London, New York: Chapman \& Hall/CRC.

Wicksell, K. (1936 [1893]). Interest and prices. London: Macmillan and Co. Ltd. The original appeared in German 1893 as Geldzins und Güterpreise. 